\title{
Reduction in Insect Attachment Caused by Different Nanomaterials Used as Particle Films (Kaolin, Zeolite, Calcium Carbonate)
}

\author{
Gianandrea Salerno $^{1}{ }^{(D}$, Manuela Rebora $^{2, *}$, Silvana Piersanti ${ }^{2} \mathbb{D}$, Valerio Saitta ${ }^{1}$, Alexander Kovalev ${ }^{3}$, \\ Elena Gorb ${ }^{3}$ and Stanislav Gorb ${ }^{3}$ (D)
}

1 Dipartimento di Scienze Agrarie, Alimentari e Ambientali, University of Perugia, Borgo XX Giugno, 06121 Perugia, Italy; gianandrea.salerno@unipg.it (G.S.); valerio.saitta@studenti.unipg.it (V.S.)

2 Dipartimento di Chimica, Biologia e Biotecnologie, University of Perugia, Via Elce di Sotto 8, 06121 Perugia, Italy; silvana.piersanti@unipg.it

3 Department of Functional Morphology and Biomechanics, Zoological Institute, Kiel University, Am Botanischen Garten 9, 24098 Kiel, Germany; akovalev@zoologie.uni-kiel.de (A.K.); egorb@zoologie.uni-kiel.de (E.G.); sgorb@zoologie.uni-kiel.de (S.G.)

* Correspondence: manuela.rebora@unipg.it; Tel.: +39-075-5855722

\section{check for} updates

Citation: Salerno, G.; Rebora, M.; Piersanti, S.; Saitta, V.; Kovalev, A.; Gorb, E.; Gorb, S. Reduction in Insect Attachment Caused by Different Nanomaterials Used as Particle Films (Kaolin, Zeolite, Calcium Carbonate). Sustainability 2021, 13, 8250 . https://doi.org/10.3390/ su13158250

Academic Editor: José Manuel Mirás-Avalos

Received: 25 June 2021

Accepted: 21 July 2021

Published: 23 July 2021

Publisher's Note: MDPI stays neutral with regard to jurisdictional claims in published maps and institutional affiliations.

Copyright: (c) 2021 by the authors. Licensee MDPI, Basel, Switzerland. This article is an open access article distributed under the terms and conditions of the Creative Commons Attribution (CC BY) license (https:// creativecommons.org/licenses/by/ $4.0 /)$.
Abstract: In the present investigation, we compared the reduction in attachment ability of the southern green stinkbug Nezara viridula (Hemiptera: Pentatomidae) to glass induced by three different nanoparticle (kaolin, zeolite, and calcium carbonate) films. Using traction force experiments, behavioral experiments, and scanning electron microscopy observations, we analyzed the insect attachment ability and linear speed on untreated and treated glass with the three particle films. The three nanomaterials strongly reduced insect attachment ability mainly owing to contamination of attachment pads. The ability to reduce insect attachment was different for the three tested particle films: kaolin and zeolite induced a significantly higher reduction in N. viridula safety factor than calcium carbonate. The coating of the surface was more uniform and compact in kaolin and zeolite compared to calcium carbonate particle film. Moreover, kaolin and zeolite particles can more readily adhere to $N$. viridula attachment devices, whereas calcium carbonate particles appeared less adherent to the cuticular surface compared to the two aluminosilicate (kaolin and zeolite) particles. Only the application of kaolin reduced insect linear speed during locomotion. Nanoparticle films have a great potential to reduce insect attachment ability and represent a good alternative to the use of insecticides for the control of pentatomid bugs and other pest insects.

Keywords: southern green stink bug; Nezara viridula; pulvilli; hairy pad; adhesion; aluminosilicate

\section{Introduction}

In order to reduce most of the negative effects that occur with the application of chemistry-based plant protection products, such as damage to human and animal health, bioaccumulation, insecticide resistance, environmental pollution, etc., insecticides based on nanotechnologies (nanoparticles) and inert materials have been introduced to be used in low-impact agriculture. Nanotechnology, with the development of tools for nanopesticide risk assessment [1], can provide a great opportunity to achieve a more rational use of pesticides. Nanomaterials can be employed as carriers of active ingredients, including insecticides and pheromones, or as insecticides alone (reviews in [2,3]). The mechanisms of action of the various nanoparticles against insects are different (review in [4]). Silica nanoparticles typically bind to the insect cuticle, causing the death of insects by dehydration $[5,6]$.

Except for use as carriers for pesticides or as desiccating insecticides, silica nanoparticles in agriculture received much attention in the last two decades owing to the introduction 
of the particle film technology [7]. The particle film technology is based on the use of aluminosilicates particles (kaolin and zeolites) in aqueous formulations for application to crop plants (see reviews in [2,7-9]). Aluminosilicates are very common minerals present in sedimentary rocks that have a lower environmental impact than chemical insecticides because of their inert nature. Kaolin is a white, non-swelling, non-abrasive, fine-grained, nanoplate-like aluminosilicate mineral, mainly consisting of kaolinite that easily disperses in water and that is chemically inert over a wide $\mathrm{pH}$ range. Zeolites are a broad range of microporous, crystalline aluminosilicates. They are among the most common minerals present in sedimentary rocks: the most well-known ones are clinoptilolite, erionite, chabazite, heulandite, mordenite, stilbite, and phillipsite [10]. The application of particle films on plants differently affects photosynthesis, stomatal conductance, transpiration, and water use by plants (e.g., in olive trees these parameters were lowered by kaolin treatment but not by zeolite treatment [11]). Kaolin and zeolite powder, suspended in water and applied on fruits and leaves, creates a more or less continuous white coating, once the water evaporates. This technology is beneficial for plants for different reasons: it protects plants from negatively impacting environmental conditions, like heat stress and sunburn [12-16] and insect pests [7,17-31]. The protection against insect pests by particle films is due to their interference during the host plant location and the acceptance process by the insect. Plants covered with white particle films change their visual and tactile features, and their taste and smell can change inducing repellence [7]. Moreover, a reduction in the insect ability to hold to the plant has been highlighted in Cacopsylla pyri (L.) (Hemiptera: Psyllidae) [32].

Recent traction force experiments [33] with two economically important polyphagous insect pests, belonging to two different orders and characterized by different attachment devices, such as the southern green stink bug Nezara viridula L. (Heteroptera: Pentatomidae) and the Mediterranean fruit fly Ceratitis capitata Wiedemann (Diptera: Tephritidae), demonstrated that insect attachment ability is heavily affected by kaolin particle film. Moreover, the degree of reduction in insect adhesion to the treated substrates (glass and plant leaves), compared with the untreated ones, differed according to the kind of treated substrate, depending on its initial wettability and morphology (e.g., trichome coverage) [33].

In the present investigation, using traction force experiments and behavioral tests, we compared the effects of different nanopowder-based materials, such as kaolin and zeolite, in reducing insect attachment and in affecting the walking behavior of $N$. viridula. We used this species as the model insect because this is one of the most relevant pentatomid insect pest in the world [34]. Moreover we previously performed numerous investigations on its attachment devices and attachment ability [33,35-39]. In addition to the two aluminosilicate nanomaterials, we also tested calcium carbonate (slaked lime dissolved in water and dried in air conditions), one of the first minerals used in "ancient particle film technology" and representing, alone or in mixtures, the predominant insecticidal material used in agriculture in the early 1900s [7]. Calcium carbonate is still used at present against insect pest and plant pathogens. Lime-stone-based products are reported as oviposition deterrent for Rhagoletis indifferens Curran (Diptera: Tephritidae) [40]; slaked lime treatments may reduce or repel insects [41-43].

\section{Materials and Methods}

\subsection{Insects}

Individuals of $N$. viridula were collected in the field close to Bastia Umbra (Perugia, Umbria region, Italy) in June 2019 and reared in a controlled climate chamber (14:10 lightdark rhythm, temperature $25 \pm 1{ }^{\circ} \mathrm{C}$, relative humidity $70 \pm 10 \%$ ) inside transparent plastic food containers ( $300 \mathrm{~mm} \times 195 \mathrm{~mm} \times 125 \mathrm{~mm}$ ) with mesh-covered holes (diameter: $5 \mathrm{~cm}$ ). Sunflower seeds (Helianthus annus L.) and French beans (Phaseolus vulgaris L.) were used to feed the insects.

Since no sexual dimorphism was previously observed in the attachment ability of males and females of $N$. viridula $[35,37]$, we used only one sex (males) for the experiments. 
As variations in attachment ability have been detected in N. viridula adults according to the insect age [36], only males about ten days old were tested.

\subsection{Cryo Scanning Electron Microscopy (cryo-SEM)}

The shock-frozen samples of treated (with kaolin, zeolite, or calcium carbonate particle films) hydrophilic glass and of the insect tarsi (after walking on treated glass) were studied in a scanning electron microscope (SEM) Hitachi S-4800 (Hitachi High-Technologies Corp, Tokyo, Japan) equipped with a Gatan ALTO 2500 cryo preparation system (Gatan Inc., Abingdon, UK). For details of sample preparation and mounting for cryo-SEM, see [44]. Specimens were sputter-coated in frozen conditions with gold-palladium (thickness: $10 \mathrm{~nm}$ ) and examined at $3 \mathrm{kV}$ acceleration voltage and a temperature of $-120^{\circ} \mathrm{C}$ at the cryo-stage within the microscope.

\subsection{Force Measurements}

The experiments were performed using a traction force experimental set-up. Prior to the force measurements, adults of $N$. viridula were weighed on a micro-balance (Mettler Toledo AG 204 Delta Range, Greifensee, Switzerland). Experimental insects were anaesthetized with carbon dioxide for $60 \mathrm{~s}$ and made incapable of flying by carefully gluing their forewings together using a small droplet of melted wax. One end of about 15-cm-long human hair was fixed on the insect thorax with a droplet of melted wax. Before starting the experiments, insects were left to recover for $30 \mathrm{~min}$. All the experiments were performed during the daytime at $25 \pm 1{ }^{\circ} \mathrm{C}$ temperature and $60 \pm 10 \%$ relative humidity.

The traction force experiment set-up consisted of a force sensor FORT-10 (10 g capacity; World Precision Instruments Inc., Sarasota, FL, USA) connected to a data acquisition unit MP 100 (Biopac Systems Ltd., Goleta, CA, USA) [45]. Data were recorded using AcqKnowledge 3.7.0 software (Biopac Systems Ltd., Goleta, CA, USA). The insect attached to the force sensor by means of the hair glued to its thorax was allowed to move on the test substrate in a direction perpendicular to the force sensor (and parallel to the substrate). The force generated by the insect walking horizontally on the test substrates was measured. Force-time curves were used to evaluate the maximal pulling (traction) force produced by walking insects.

N. viridula adult males were tested on different surfaces, according to the following sequence: untreated glass (glass before), treated glass (with kaolin, zeolite, or calcium carbonate films), untreated glass (glass after $0 \mathrm{~h}$ ), untreated glass after $1 \mathrm{~h}$ (glass after $1 \mathrm{~h}$ ), and untreated glass after $24 \mathrm{~h}$ (glass after $24 \mathrm{~h}$ ). Thirteen adult males of $N$. viridula were tested for each particle film. Force-time curves were used to evaluate the maximal friction force produced by pulling insects on the different test surfaces for each individual run.

\subsection{Walking Behavior}

Linear speed: insects were allowed to walk on horizontal and vertical untreated glass (and just after on glass treated with kaolin, zeolite, calcium carbonate). Their walking behavior was recorded using a monochrome CCD video camera (Sony SSC M370 CE, Sony Professional Solutions Europe, Weybridge, UK) fitted with a 12.5-75 mm/F 1.8 zoom lens. Analog video signals from the camera were digitized by a video frame grabber (Canopus ADVC 110, Grass Valley, CA, USA). Digitized data were processed by XBug, a video tracking and motion analysis software [46]. The insect linear speed during the entire bioassay was calculated.

Attachment in free-walking insects: each insect was placed on a horizontal treated glass plate, and the plate was gently inverted $\left(180^{\circ}\right)$. Only insects that remained attached were used in further experiments. This allowed us to select undamaged bugs.

Each undamaged insect was placed on a horizontal treated glass (with kaolin, zeolite, or calcium hydroxide), and the glass was gently rotated at $90^{\circ}$ and then at $180^{\circ}$. Just after, all the insects were tested on untreated glass using the same procedure. The number of insects able to remain attached to each surface was recorded. 


\subsection{Substrate Preparation and Characterization}

The hydrophilic glass (water contact angle: $47.06 \pm 3.37^{\circ}$ (mean \pm SD)) bearing different particle films (kaolin, zeolite, and calcium carbonate) was prepared as follows:

- By spraying the glass surface with a water suspension of kaolin powder commonly available in Italy ("I consigli dell'esperto", Civitavecchia, Italy) at the rate of $4 \%(w / v)$. The suspension was applied on horizontal surfaces with a hand-sprayer until runoff. - By spraying the glass surface with a water suspension of zeolite powder commonly available in Italy (Bioagrotech, Repubblica di San Marino, Italy-clinoptilolite -heulandite $67.5 \%$ and mordenite $32.5 \%$,) at the rate of $0.4 \%(w / v)$. The suspension was applied on horizontal surfaces with a hand-sprayer until runoff.

- $\quad$ By painting the glass surface with a water suspension of calcium hydroxide powder (or hydrated lime $\left[\mathrm{Ca}(\mathrm{OH})_{2}\right]$ ) (Sigma Aldrich, St Louis, MI, USA) at the rate of 1:1 using a brush.

After spraying or painting, the surfaces were left to dry at a room temperature. The wettability of untreated glass and treated glass surfaces was characterized by measuring the contact angles of water (aqua millipore, droplet size $=1 \mu \mathrm{L}$, sessile drop method) using a high-speed optical contact angle measuring instrument OCAH 200 (Dataphysics Instruments $\mathrm{GmbH}$, Filderstadt, Germany). Ten measurements $(n=10)$ were performed for each substrate.

The roughness of treated and untreated substrates was characterized using the white light interferometer NewView 6000 (Zygo, Middlefield, CT, USA) with the objectives $\times 5$ and $\times 50$ (window size $1400 \cdot \mu \mathrm{m} \times 1050 \cdot \mu \mathrm{m}$ and $140 \cdot \mu \mathrm{m} \times 105 \cdot \mu \mathrm{m}$, respectively). Five individual measurements $(n=5)$ at different sites were performed for each substrate.

\subsection{Statistical Analysis}

In the traction force experiments, the difference of safety factors (friction force divided by the insect weight) on treated and untreated glass was analyzed with the Wilcoxon matched pairs test. The percentage of reduction in the safety factor of $N$. viridula on glass covered by the different particle films (kaolin, zeolite, and calcium carbonate) in relation to the untreated glass was analyzed using the Kruskall-Wallis ANOVA followed by multiple comparisons. The difference in linear speed of $N$. viridula walking on untreated glass and treated (with kaolin, zeolite, or calcium carbonate) glass was evaluated by Student's $t$-tests for dependent samples. The comparisons of safety factor of N. viridula on untreated glass before and after walking on treated surfaces (kaolin, zeolite, and calcium carbonate) at different time intervals (after $0 \mathrm{~h}, 1 \mathrm{~h}$, and $24 \mathrm{~h}$ ) were done using a repeated measure ANOVA followed by the Dunnett test [47]. Before parametric analysis, the data were subjected to Box-Cox transformations, in order to reduce data heteroscedasticity [48].

\section{Results}

\subsection{Characterization of Tested Surfaces}

The kaolin particle film on glass, visualized with cryo-SEM (Figure 1a-c), at low magnification appears as a uniform coverage encrusting the surface (Figure 1a). At higher magnification, the film appears to be constituted of many layers of polygonal-shaped, horizontally placed plates (Figure $1 \mathrm{~b}, \mathrm{c}$ ). The kaolin particle film has a water contact angle of about $14^{\circ}$ (for just released water drop), with water drops spreading very quickly over the surface and completely absorbed in a short (about $4.5 \mathrm{~s}$ ) time. Roughness Ra is $2.00 \pm 0.08 \mu \mathrm{m}$ at $5 \times$ and $1.54 \pm 0.09 \mu \mathrm{m}$ at higher $(50 \times)$ magnification (Figure $2 \mathrm{c}, \mathrm{d}$, Table 1). 

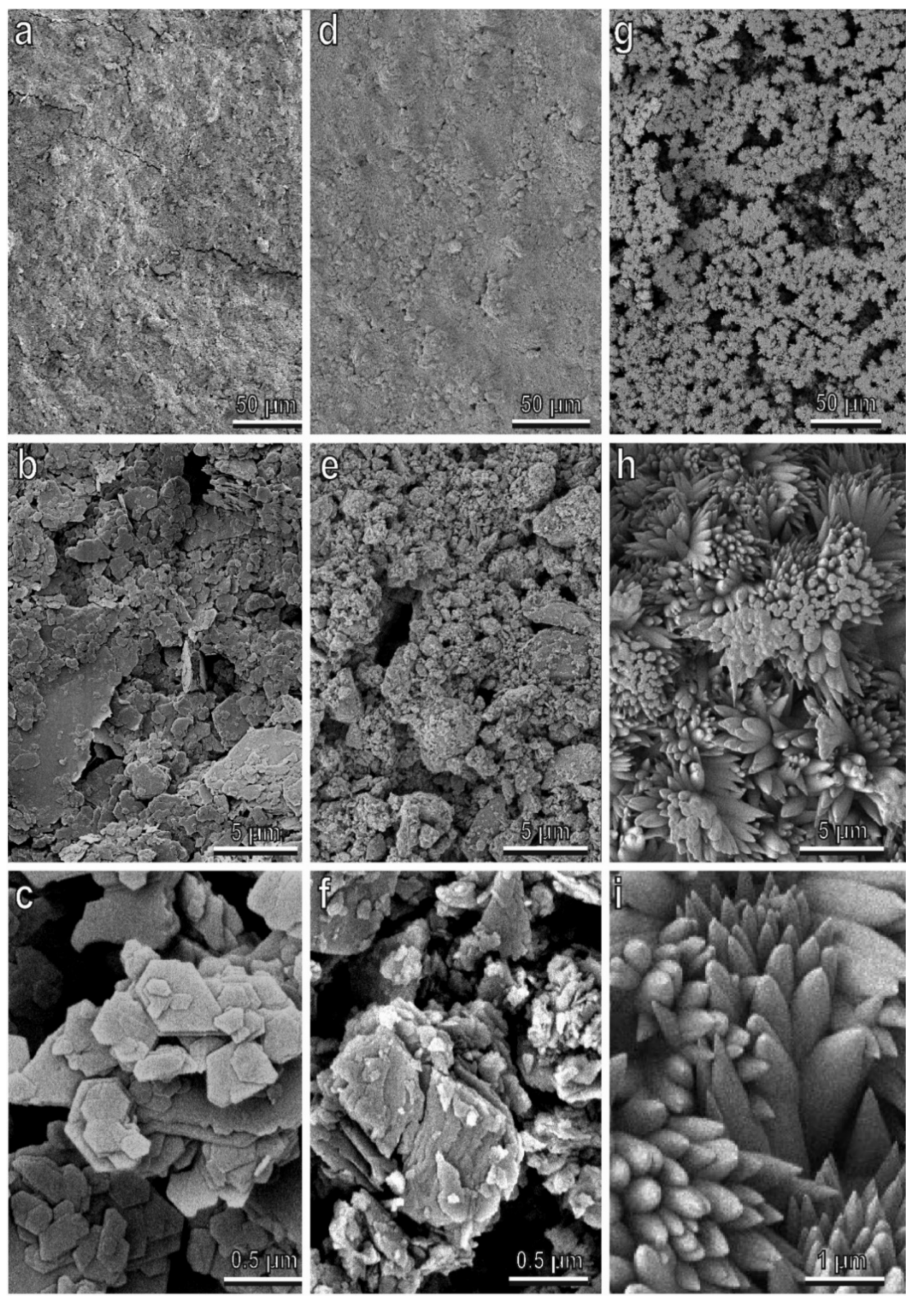

Figure 1. Kaolin $(\mathbf{a}-\mathbf{c})$, zeolite $(\mathbf{d}-\mathbf{f})$, and calcium carbonate $(\mathbf{g}-\mathbf{i})$ particle film sprayed on glass, visualized with cryo-SEM at progressively higher magnifications (from $(\mathbf{a}, \mathbf{d}, \mathbf{g})$ to $(\mathbf{c}, \mathbf{f}, \mathbf{i})$, respectively). (a) Uniform film encrusting the surface; $(\mathbf{b}, \mathbf{c})$ layers of polygonal-shaped, horizontally placed plates; (d) uniform film encrusting the surface; (e,f) plates with variable shapes and dimensions forming groups oriented at different angles to the surface; (g) non-uniform film consisting of flower-shaped crystals forming groups separated from each other; (h,i) flower-shaped crystals at higher magnifications composed of numerous pointed digitations.
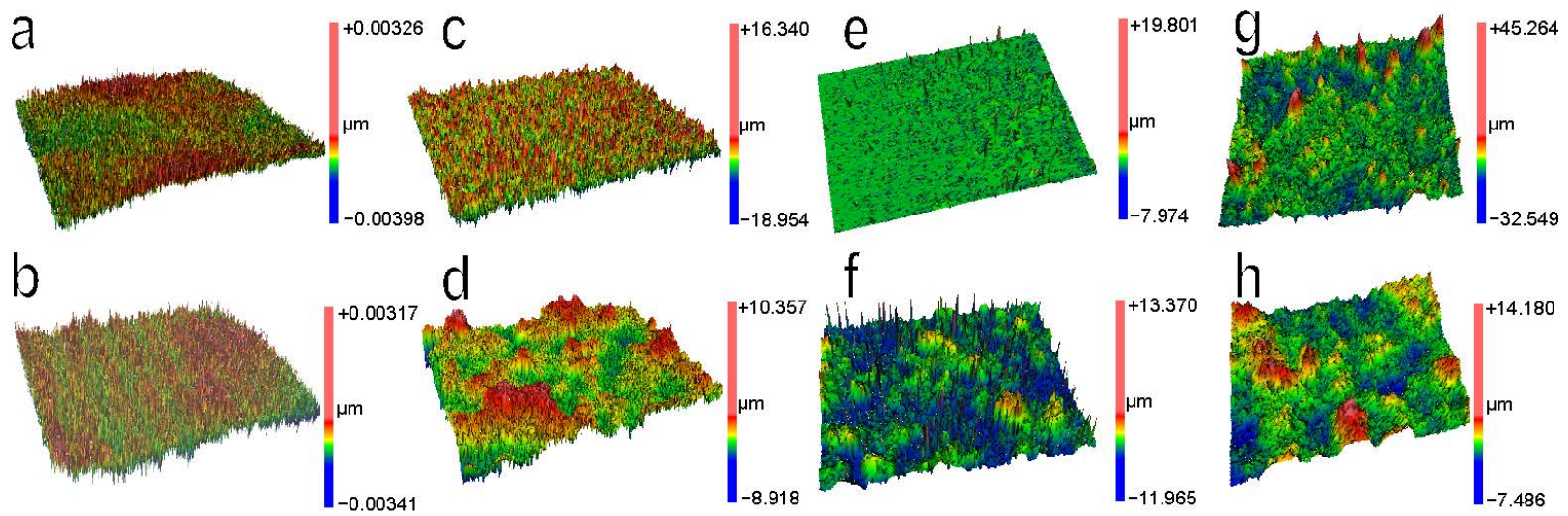

Figure 2. 3D surface profiles of untreated $(\mathbf{a}, \mathbf{b})$ and treated glass $(\mathbf{c}-\mathbf{h})$, with kaolin $(\mathbf{c}, \mathbf{d})$, zeolite $(\mathbf{e}, \mathbf{f})$, and calcium carbonate (g,h) particle film. The long side length equals to $1400 \mu \mathrm{m}(\mathbf{a}, \mathbf{c}, \mathbf{e}, \mathbf{g})$ and $140 \mu \mathrm{m}(\mathbf{b}, \mathbf{d}, \mathbf{f}, \mathbf{h})$ (see Table 1). 
Table 1. Roughness characteristics of test substrates (see Figure 2).

\begin{tabular}{|c|c|c|c|c|}
\hline Surfaces & $\operatorname{Ra}(5 \times)$ & $\operatorname{Ra}(50 \times)$ & rms $(5 \times)$ & rms $(50 \times)$ \\
\hline Untreated glass & $0.55 \pm 0.03 \mathrm{~nm}$ & $0.52 \pm 0.01 \mathrm{~nm}$ & $0.70 \pm 0.04 \mathrm{~nm}$ & $0.65 \pm 0.01 \mathrm{~nm}$ \\
\hline Treated glass (with kaolin particle film) & $2.00 \pm 0.08 \mu \mathrm{m}$ & $1.54 \pm 0.09 \mu \mathrm{m}$ & $2.58 \pm 0.10 \mu \mathrm{m}$ & $1.93 \pm 0.11 \mu \mathrm{m}$ \\
\hline Treated glass (with zeolite particle film) & $1.66 \pm 0.30 \mu \mathrm{m}$ & $2.22 \pm 0.30 \mu \mathrm{m}$ & $2.13 \pm 0.33 \mu \mathrm{m}$ & $2.81 \pm 0.20 \mu \mathrm{m}$ \\
\hline Treated glass (with calcium carbonate particle film) & $4.5 \pm 0.40 \mu \mathrm{m}$ & $2.16 \pm 0.44 \mu \mathrm{m}$ & $6.25 \pm 0.61 \mu \mathrm{m}$ & $2.77 \pm 0.61 \mu \mathrm{m}$ \\
\hline
\end{tabular}

Ra, roughness average (absolute value of the surface height averaged over the surface); rms, root mean square or quadratic mean (a statistical measure of the magnitude of a varying quantity). Data are presented as mean \pm s.e.m.

The zeolite particle film on glass, visualized with cryo-SEM (Figure 1d-f), at low magnification looks similar to the kaolin particle film but with a reduced roughness compared to kaolin (Figure 1d). At higher magnification, the film appears to be constituted of many plates with variable shapes and dimensions forming groups oriented at different angles to the surface (Figure 1e,f). The zeolite particle film is characterized by a water contact angle of about $40^{\circ}$ (for just-released water drops), where water drops spread very quickly over the surface and are completely absorbed in a very short (about $2 \mathrm{~s}$ ) time. The roughness $(\mathrm{Ra})$ was $66 \pm 0.30 \mu \mathrm{m}$ at $5 \times$ and $2.22 \pm 0.30 \mu \mathrm{m}$ at $50 \times$ (Figure 2e,f, Table 1 ).

The calcium carbonate particle film on glass, visualized with cryo-SEM (Figure 1g-i), at low magnification appeared as a non-uniform layer composed of flower-shaped crystals forming groups separated from each other (Figure 1g). These crystals at higher magnifications consist of numerous pointed digitations (Figure $1 \mathrm{~h}, \mathrm{i}$ ). The calcium hydroxide particle film was characterized by a water contact angle of about $8^{\circ}$ (for just-released water drops); water drops spread very quickly over the surface and were completely absorbed in an extremely short (less than $0.5 \mathrm{~s}$ ) time. The roughness (Ra) was $4.5 \pm 0.40 \mu \mathrm{m}$ at $5 \times$ magnification and $2.16 \pm 0.44 \mu \mathrm{m}$ at $50 \times$ magnification (Figure $2 \mathrm{~g}$,h, Table 1 ).

\subsection{Attachment Ability of Nezara viridula Adults to Untreated and Treated Glass}

In the traction force experiments, the safety factors (traction force divided by the insect weight) were significantly decreased on all the treated surfaces bearing different particle films compared to untreated glass (Figure 3) (Wilcoxon matched pairs test; kaolin: $Z=3.06$, $n=12, p=0.002$; zeolite: $\mathrm{Z}=3.30, n=14, p=0.001$; calcium carbonate: $\mathrm{Z}=3.18, n=13$, $p=0.002)$. The percentage of reduction in the safety factor obtained on surfaces treated with kaolin, in relation to the untreated glass, was not significantly different from that on surfaces treated with zeolite. Both particle films (kaolin and zeolite) induced a percentage of reduction in the safety factor significantly higher than calcium carbonate particle film (Kruskall-Wallis ANOVA: $\mathrm{H}_{2,39}=20.89, p<0.0001$ ) (Figure 4).

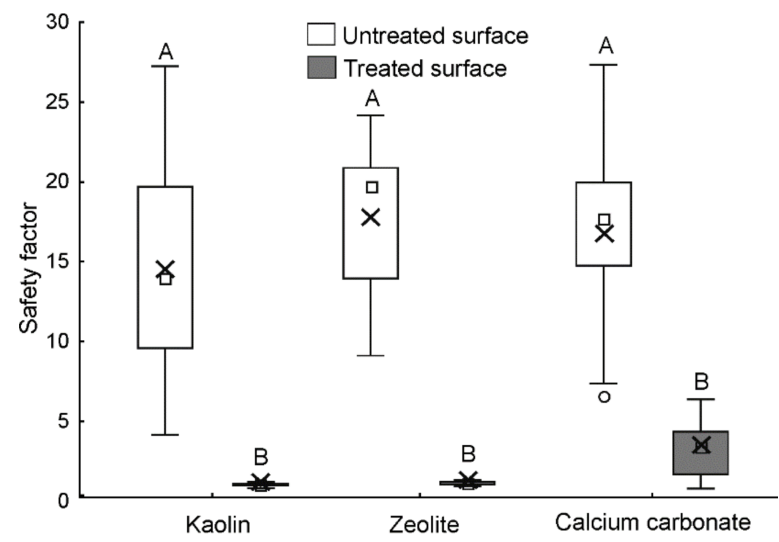

Figure 3. Safety factor (traction force divided by the insect weight) obtained in traction force experiments with Nezara viridula on treated (covered by kaolin, zeolite, or calcium carbonate) and untreated glass. Boxplots show the interquartile range and the median (square), whiskers indicate $1.5 \times$ interquartile range, and $\times$ shows the arithmetic mean. Boxplots with different letters are significantly different at $p<0.05$, Wilcoxon matched pairs test. 


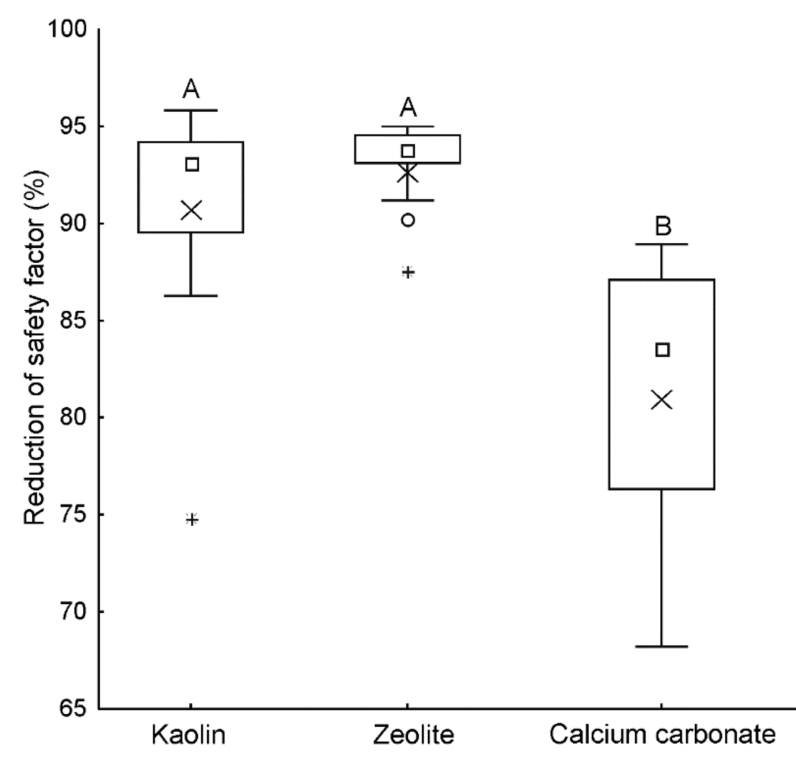

Figure 4. Percentage of reduction in the safety factor of Nezara viridula on glass covered by the different particle films (kaolin, zeolite, and calcium carbonate) in relation to the untreated glass. Boxplots show the interquartile range and the median (square), whiskers indicate $1.5 \times$ interquartile range, $\times$ shows the arithmetic mean, ${ }^{\circ}$ shows the outliers and + shows the extremes. Boxplots with different letters are significantly different at $p<0.05$, Kruskall-Wallis ANOVA followed by multiple comparisons.

As for the linear speed of walking $N$. viridula insects on horizontal glass, there was a significant reduction on glass treated with kaolin compared to untreated glass $(\mathrm{t}=2.31$, d.f. $=18, p=0.0330)$, whereas both glass treated with zeolite $(t=0.86$, d.f. $=19, p=0.401)$ and calcium hydroxide $(\mathrm{t}=0.13$, d.f. $=18, p=0.895)$ did not differ compared with untreated glass (Figure 5). It was not possible to record the linear speed on vertical glass because, as demonstrated below, the insects were not able to walk on vertical, treated surfaces.

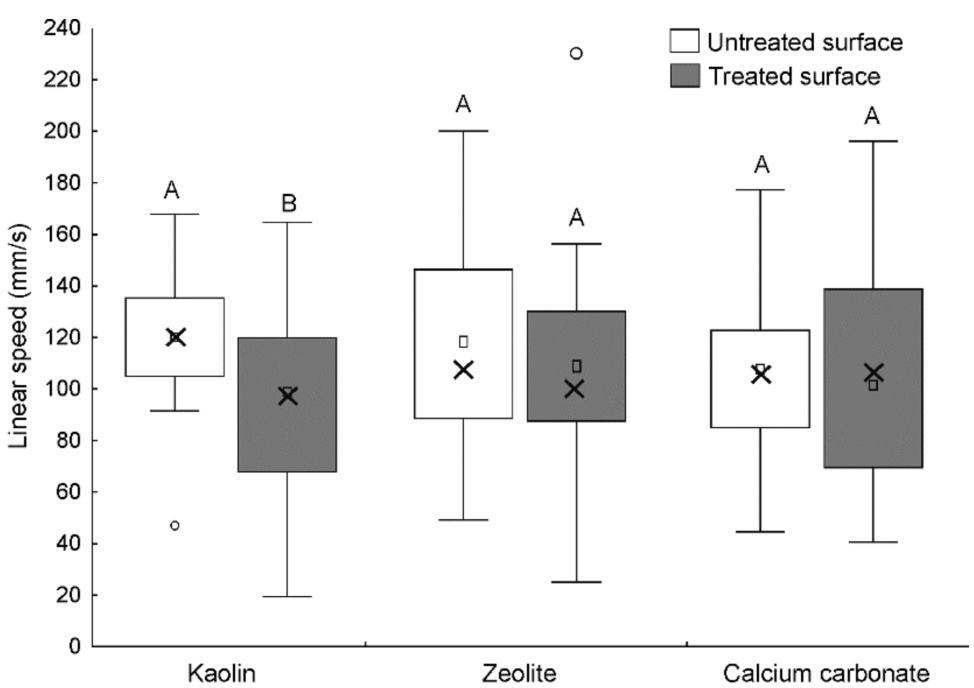

Figure 5. Linear speed of Nezara viridula walking on untreated glass and treated glass (with kaolin, zeolite or calcium carbonate). Boxplots show the interquartile range and the median (square), whiskers indicate $1.5 \times$ interquartile range, $\times$ shows the arithmetic mean and ${ }^{\circ}$ shows the outliers. Boxplots with different letters are significantly different at $p<0.05$. Boxplots with different letters are significantly different at $p<0.05$, Student's $t$-tests for dependent samples. 
In the experiments with rotated and inverted substrates, the percentage of insects able to remain attached to the surface rotated at $90^{\circ}$ was not statistically different among the three particle films (Fisher's exact test: $p=0.31$ ): it was $0 \%$ for both kaolin and zeolite and $20 \%$ for calcium carbonate. When the treated glass was inverted (at $180^{\circ}$ ), the percentage of insects able to remain attached to the surface was $0 \%$ for all three treated substrates. When these insects, after walking on a treated substrate, were allowed to walk on untreated glass, all of them remained attached to the surface when it was rotated at both $90^{\circ}$ and at $180^{\circ}$.

\subsection{Evaluation of the Contaminating Effect of Different Nanoparticle Films}

For traction force experiments performed on glass before and after walking on treated surfaces (kaolin, zeolite, and calcium carbonate) at different time intervals, i.e., after $0 \mathrm{~h}$, after $1 \mathrm{~h}$, and after $24 \mathrm{~h}$, the insect safety factor on untreated glass just after walking on treated surfaces was significantly different for kaolin (repeated measure ANOVA: $\mathrm{F}_{3,36}=3.03, p=0.0418$ ) and zeolite (repeated measure ANOVA: $\mathrm{F}_{3,36}=4.17, p=0.0123$ ) only if tests were compared after $0 \mathrm{~h}$, but not after 1 or $24 \mathrm{~h}$. For calcium carbonate, no significant difference was found (repeated measure ANOVA: $\mathrm{F}_{3,36}=2.64, p=0.0640$ ) (Figure 6).

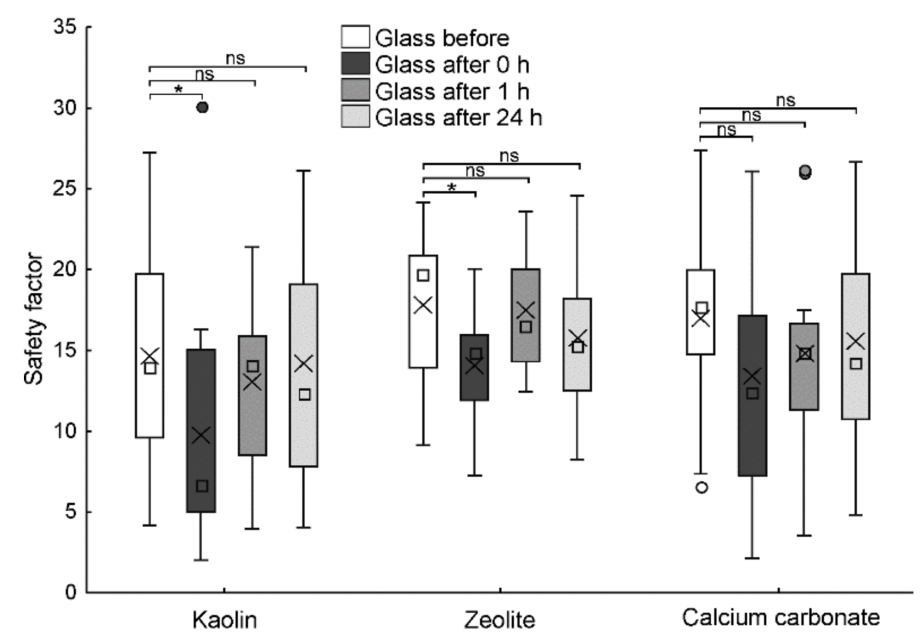

Figure 6. Safety factor (traction force divided by the insect weight) of Nezara viridula on untreated glass, before and after walking on treated surfaces (kaolin, zeolite, and calcium carbonate) at different time intervals $(0 \mathrm{~h}, 1 \mathrm{~h}$, and $24 \mathrm{~h})$. Boxplots show the interquartile range and the median (square), whiskers indicate $1.5 \times$ interquartile range, $\times$ shows the arithmetic mean and ${ }^{\circ}$ shows the outliers. In the comparison between the safety factor on glass before and after walking on treated surfaces, an asterisk $\left(^{*}\right)$ means significantly different at $p<0.05$, and ns means not significantly different (repeated measure ANOVA, Dunnett test).

Cryo-SEM investigations of the tarsal attachment devices of $N$. viridula males just after they walked on treated substrates (kaolin, zeolite, and calcium carbonate) (Figure 7) revealed that both the smooth pads (pulvilli) and the basitarsal hairy pad of the bugs were contaminated by the particles. In particular, the smooth pulvilli appear covered by crusts formed by kaolin (Figure 7a) or zeolite (Figure 7e) particles glued together. Moreover, kaolin (Figure $7 \mathrm{~b}-\mathrm{d}$ ) or zeolite (Figure $7 \mathrm{f}-\mathrm{h}$ ) particles accumulated among the adhesive setae of the hairy pad. Calcium carbonate particles were visible on the ventral side of pulvilli (Figure 7i) and among the basitarsal adhesive setae (Figure 7j-1), but they appeared less adherent to the cuticular surface compared to the two aluminosilicate particles. 

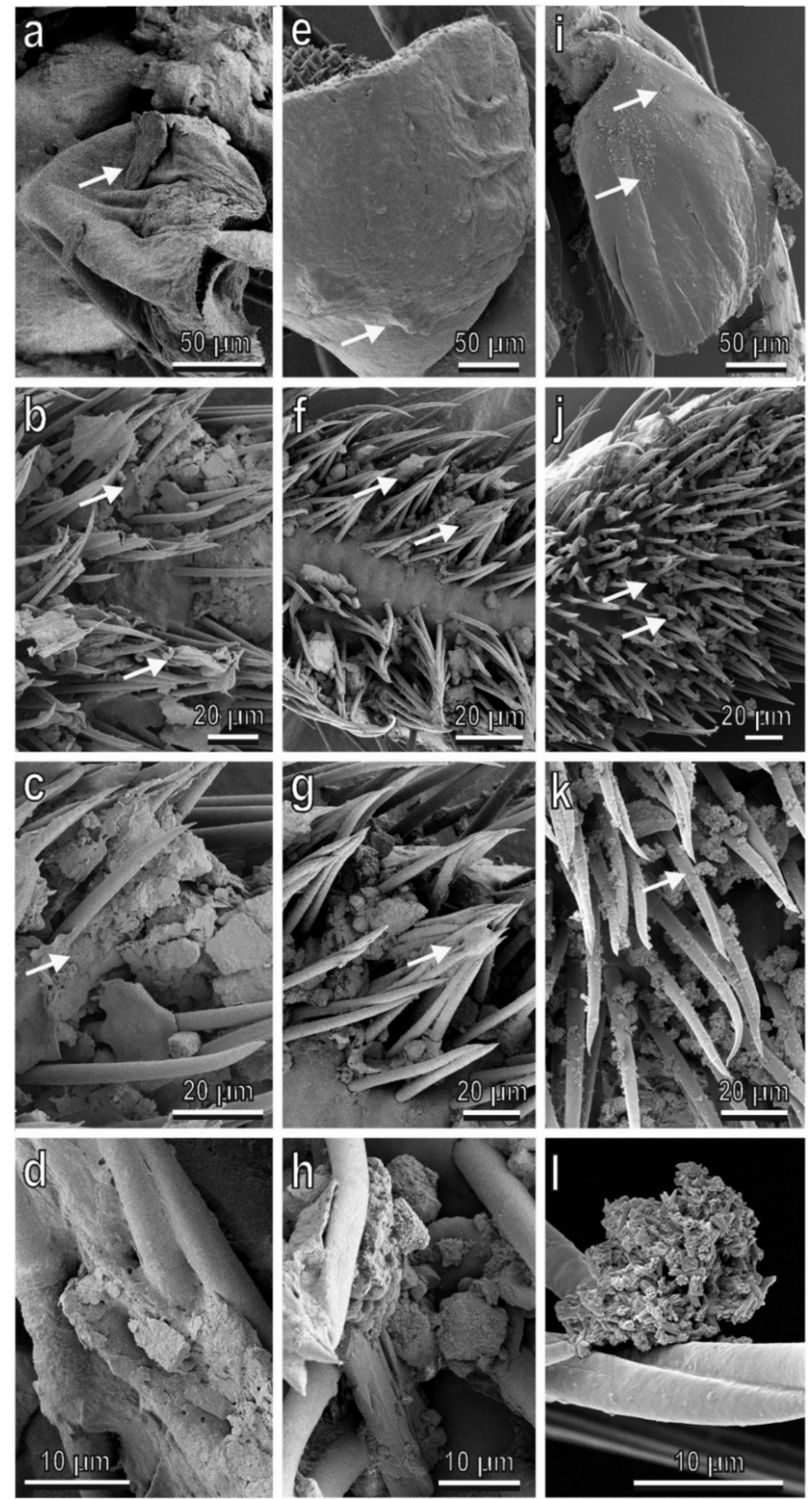

Figure 7. Ventral side of the tarsal attachment devices of Nezara viridula males just after they walked on glass treated with the different particle films, kaolin $(\mathbf{a}-\mathbf{d})$, zeolite $(\mathbf{e}-\mathbf{h})$, and calcium carbonate $(\mathbf{i}-\mathbf{l})$, visualized with cryo-SEM. Both pulvilli $(\mathbf{a}, \mathbf{e}, \mathbf{i})$ and basitarsal hairy pads $(\mathbf{b}-\mathbf{d}, \mathbf{f}-\mathbf{h}, \mathbf{j}-\mathbf{l})$ are contaminated by the particles (arrows). Note that kaolin and zeolite particles form crusts on the ventral surface of pulvilli $(\mathbf{a}, \mathbf{e})$ and strictly adhere to the adhesive setae $(\mathbf{b}-\mathbf{d}, \mathbf{f}-\mathbf{h})$, while calcium carbonate particles are visible on the ventral side of pulvilli (i) and among the basitarsal adhesive setae $(\mathbf{k}, \mathbf{l})$, but they appear less adherent to the insect cuticular surface compared with the two aluminosilicate particles.

\section{Discussion}

The present investigation focusing on the effect by different nanomaterials used as particle films, such as kaolin, zeolite, and calcium carbonate, on attachment ability of $N$. viridula reveals that the three nanomaterials can reduce insect attachment. This is clearly demonstrated by the traction force experiments as well as by tests with free-walking insects. Such results corroborate the role of particle films in pest management to alter the behavior of pest insects not only before but also after their contact with the plant [32]. Particle films covering leaves with a white coating, not only can prevent insects from recognizing 
the leaf surface [49] but can also heavily affect their holding to plant surfaces, as recently demonstrated in N. viridula [33].

The strong reduction in attachment of $N$. viridula insects to the substrate due to the different particle films observed in the present investigations may help to explain the results of field experiments performed on an invasive pentatomid bugs, such as the brown marmorated stink bugs Halyomorpha halys (Stål) (Hemiptera: Pentatomidae), where kaolin applications to peppers resulted in significantly less stink-bug-injured fruits compared to the untreated control in all harvests [50]. Further field investigations are necessary to evaluate the potential role of particle films in reducing the impact of these pest species on agriculture. Previous laboratory experiments demonstrated that the degree of reduction in insect adhesion to the substrates treated with kaolin (glass and plant leaves) differed according to the kind of treated substrate, depending on its initial wettability and morphology (e.g., trichome coverage) of plant leaves [33]. Indeed a reduced percentage of covered area of kaolin occurs on treated hydrophobic plant leaves such as the adaxial leaf side of Prunus laurocerasus showing 2D epicuticular wax film/layer, where kaolin film forms round-shaped dry droplets. In the case of Helianthus annuus, the dense pubescence of the adaxial leaf side composed by three types of trichomes causes no significant reduction in the $N$. viridula friction force on the treated leaf of this plant. In this regard, it would be interesting to compare the role of particle films in reducing pest impact on different crops.

We believe that the main mechanism of action of all these particle film in reducing insect adhesion is due to contamination of insect attachment organs, as it has already been shown for kaolin particle film [33] and is clearly visible also for zeolite and calcium hydroxide in our SEM observations. Indeed, both the pulvilli and the basitarsal hairy pad of $N$. viridula males just after they walked on glass covered with kaolin, zeolite, or calcium hydroxide were heavily contaminated by the particles. We also cannot exclude a role of tarsal fluid absorption, since aluminosilicates represent a potential adsorbent due to their microporous structures capable of adsorbing molecules at relatively low pressure [51]. The three particle films studied here have a high absorption ability, as shown in our water contact angle measurement experiments. As insect adhesion is also mediated by fluid, absorption of the secretion fluid from insect adhesive pads by porous media reduces insect adhesion $[45,52]$.

The ability to reduce insect attachment is different for the three tested particle films. Kaolin and zeolite induced a significantly higher percentage of reduction in N. viridula safety factor than the calcium carbonate particle film did. Such an ability of the two aluminosilicates compared to calcium hydroxide can be due to different reasons. Indeed, our SEM observations showed that the coating of the surface is more uniform and compact in kaolin and zeolite compared to the calcium hydroxide particle film. Moreover, kaolin and zeolite particles glued together and formed crusts on the ventral surface of N. viridula pulvilli and can strictly adhere to the adhesive setae of the hairy pads, whereas calcium carbonate particles appeared less adherent to the insect cuticular surface. The higher and more persistent contamination and, consequently, the reduction in insect attachment on kaolin and zeolite films compared with calcium hydroxide film was confirmed also in the experiments with $N$. viridula walking on glass at different time intervals after walking on treated surfaces. Here, we observed a reduction in insect attachment on glass after walking on kaolin and zeolite, whereas no significant difference has been detected for calcium hydroxide. In any case, the reduction in the attachment ability of N. viridula recovers in a short time (after $1 \mathrm{~h}$, the attachment ability on glass was completely gained) for all the particle films and this is due to the self-cleaning ability of fluid-based smooth and hairy adhesive systems of insects [53,54].

In consideration that a reduction in the walking speed in the larvae of Cydia pomonella (L.) (Lepidoptera: Tortricidae) on plants covered by kaolin film has been reported [18], we compared the linear speed on glass treated with the three particle films. In these experiments on vertical glass, the insects were not able to attach at all, demonstrating that the used coatings effectively prevent insect crawling on vertical surfaces such as plant 
stems. In the experiments on horizontal glass, we could observe that only kaolin reduced the insect linear speed. It remains unclear why such a reduction is caused only by kaolin and not by zeolite, although the surface roughness is similar in both kaolin and zeolite, and the particles seem to contaminate the insect attachment devices in the same way. Further investigations are necessary to clarify this point.

In conclusion, interest in natural and artificial coatings preventing insect adhesion is high (see review in [55]), and the present study deepens the knowledge of the interaction of nanoscale particle films and insects, which can contribute to the promotion of nanoparticles to become important components of an integrated pest-management-based strategy.

Author Contributions: The study was designed by all the authors. S.G. performed the cryo-scanning electron microscopy investigations. M.R. and G.S. performed the traction force experiments. S.P. and V.S. performed the walking behavior experiments. E.G. and A.K. characterized the surfaces (roughness and water contact angle). The manuscript was written by M.R., G.S., E.G., and S.G. All authors discussed the analysis and interpretation of the results and participated in the final editing of the manuscript. All authors have read and agreed to the published version of the manuscript.

Funding: This research received no external funding.

Institutional Review Board Statement: Not applicable.

Data Availability Statement: The data presented in this study are available on request from the corresponding author.

Acknowledgments: The research was performed thanks to the knowledge acquired during training stages at the Department of Functional Morphology and Biomechanics of the University of Kiel supported by Erasmus grants (staff mobility for training 2019-20 (MR) and (GS)).

Conflicts of Interest: The authors declare no conflict of interest.

\section{References}

1. Villaverde, J.J.; Sevilla-Morán, B.; López-Goti, C.; Alonso-Prados, J.L.; Sandín-España, P. Considerations of nano-QSAR/QSPR models for nanopesticide risk assessment within the European legislative framework. Sci. Total Environ. 2018, 634, 1530-1539. [CrossRef] [PubMed]

2. Eroglu, N.; Emekci, M.; Athanassiou, C.G. Applications of natural zeolites on agriculture and food production. J. Sci. Food Agric. 2017, 97, 3487-3499. [CrossRef] [PubMed]

3. Athanassiou, C.G.; Kavallieratos, N.G.; Benelli, G.; Losic, D.; Usha Rani, P.; Desneux, N. Nanoparticles for pest control: Current status and future perspectives. J. Pest Sci. 2018, 91, 1-15. [CrossRef]

4. Benelli, G. Mode of action of nanoparticles against insects. Environ. Sci. Pollut. Res. 2018, 25, 12329-12341. [CrossRef] [PubMed]

5. Bhattacharyya, A.; Bhaumik, A.; Rani, P.U.; Mandal, S.; Epidi, T.T. Nano-particles-A recent approach to insect pest control. Afr. J. Biotechnol. 2010, 9, 3489-3493.

6. Kavallieratos, N.G.; Athanassiou, C.G.; Korunic, Z.; Mikeli, N.H. Evaluation of three novel diatomaceous earths against three stored-grain beetle species on wheat and maize. Crop Prot. 2015, 75, 132-138. [CrossRef]

7. Glenn, D.M.; Puterka, G.J. Particle films: A new technology for agriculture. Hortic. Rev. 2005, 31, 1-44.

8. Ramesh, K.; Reddy, D.D. Zeolites and their potential uses in agriculture. Adv. Agron. 2011, 113, $219-241$.

9. De Smedt, C.; Someus, E.; Spanoghe, P. Potential and actual uses of zeolites in crop protection. Pest Manag. Sci. 2015, 71, 1355-1367. [CrossRef]

10. Payra, P.; Dutta, P.K. Zeolites: A primer. In Handbook of Zeolite Science and Technology; Auerbach, S.M., Carrado, K.A., Dutta, P.K., Eds.; Marcel Dekker: New York, NY, USA, 2003; pp. 1-19.

11. Rotondi, A.; Morrone, L.; Facini, O.; Faccini, B.; Ferretti, G.; Coltorti, M. Distinct particle films impacts on olive leaf optical properties and plant physiology. Foods 2021, 10, 1291. [CrossRef]

12. Glenn, D.M.; Prado, E.; Erez, A.; McFerson, J.; Puterka, G.J. A reflective, processed-kaolin particle film affects fruit temperature, radiation reflection, and solar injury in apple. J. Am. Soc. Hortic. Sci. 2002, 127, 188-193. [CrossRef]

13. Jifon, J.L.; Syvertsen, J.P. Kaolin particle film applications can increase photosyntesis and water use efficiency of Ruby Red grapefruit leaves. J. Am. Soc. Hortic. Sci. 2003, 128, 107-112. [CrossRef]

14. Melgarejo, P.; Martínez, J.J.; Hernández, F.; Martínez-Font, R.; Barrows, P.; Erez, A. Kaolin treatment to reduce pomegranate sunburn. Sci. Hortic. 2004, 100, 349-353. [CrossRef]

15. Gindaba, J.; Wand, S.J.E. Do fruit sunburn control measures affect leaf photosynthetic rate and stomatal conductance in Royal Gala apple? Environ. Exp. Bot. 2007, 59, 160-165. [CrossRef]

16. De Smedt, C.; Steppe, K.; Spanoghe, P. Beneficial effects of zeolites on plant photosynthesis. Adv. Mater. Sci. 2017, 2, 1-11. [CrossRef] 
17. Puterka, G.J.; Glenn, D.M.; Sekutowski, D.G.; Unruh, T.R.; Jones, S.K. Progress toward liquid formulations of particle films for insect and disease control in pear. Environ. Entomol. 2000, 29, 329-339. [CrossRef]

18. Unruh, T.R.; Knight, A.L.; Upton, J.; Glenn, D.M.; Puterka, G.J. Particle films for suppression of the codling moth (Lepidoptera: Tortricidae) in apple and pear orchards. J. Econ. Entomol. 2000, 93, 737-743. [CrossRef]

19. Saour, G.; Makee, H. A kaolin-based particle film for suppression of the olive fruit fly Bactrocera oleae Gmelin (Diptera: Tephritidae) in olive groves. J. Appl. Entomol. 2004, 128, 28-31. [CrossRef]

20. Daniel, C.; Pfammatter, W.; Kehrli, P.; Wyss, E. Processed Kaolin as an alternative insecticide against the European pear sucker, Cacopsylla pyri (L.). J. Appl. Entomol. 2005, 129, 363-367. [CrossRef]

21. Saour, G. Morphological assessment of olive seedlings treated with kaolin-based particle film and biostimulant. Adv. Hortic. Sci. 2005, 19, 193-197.

22. Bostanian, N.J.; Racette, G. Particle film for managing arthropod pests. J. Econ. Entomol. 2008, 101, 145-150. [CrossRef]

23. Pascual, S.N.; Cobos, G.; Seris, E.; González-Núñez, M. Effects of processed kaolin on pests and non-target arthropods in a Spanish olive grove. J. Pest Sci. 2009, 83, 121-133. [CrossRef]

24. D'Aquino, S.; Cocco, A.; Ortu, S.; Schirra, M. Effects of kaolin-based particle film to control Ceratitis capitata (Diptera: Tephritidae) infestations and postharvest decay in citrus and stone fruit. Crop Prot. 2011, 30, 1079-1086. [CrossRef]

25. Lo Verde, G.; Caleca, V.; Lo Verde, V. The use of kaolin to control Ceratitis capitata in organic citrus groves. Bull. Insectol. 2011, 64, 127-134.

26. Nateghi, M.F.; Paknejad, F.; Moarefi, M. Effect of concentrations and time of kaolin spraying on wheat aphid. J. Biol. Environ. Sci. 2013, 7, 163-168.

27. Silva, C.A.D.; Ramalho, F.S. Kaolin spraying protects cotton plants against damages by boll weevil Anthonomus grandis Boheman (Coleoptera: Curculionidae). J. Pest Sci. 2013, 86, 563-569. [CrossRef]

28. De Smedt, C.; Van Damme, V.; De Clercq, P.; Spanoghe, P. Insecticide Effect of Zeolites on the Tomato Leafminer Tuta absoluta (Lepidoptera: Gelechiidae). Insects 2016, 7, 72. [CrossRef] [PubMed]

29. Tacoli, F.; Mori, N.; Pozzebon, A.; Cargnus, E.; Da Vià, S.; Zandigiacomo, P.; Duso, C.; Pavan, F. Control of Scaphoideus titanus with natural products in organic vineyards. Insects 2017, 8, 129. [CrossRef] [PubMed]

30. Tacoli, F.; Pavan, F.; Cargnus, E.; Tilatti, E.; Pozzebon, A.; Zandigiacomo, P. Efficacy and mode of action of kaolin in the control of Empoasca vitis and Zygina rhamni (Hemiptera: Cicadellide) in vineyards. J. Econ. Entomol. 2017, 110, 1164-1178. [CrossRef] [PubMed]

31. Tacoli, F.; Cargnus, E.; Kiaeian Moosavi, F.; Zandigiacomo, P.; Pavan, F. Efficacy and mode of action of kaolin and its interaction with bunch-zone leaf removal against Lobesia botrana on grape-vines. J. Pest Sci. 2019, 92, 465-475. [CrossRef]

32. Puterka, G.J.; Glenn, D.M.; Pluta, R.C. Action of particle films on the biology and behavior of pear psylla (Homoptera: Psyllidae). J. Econ. Entomol. 2005, 98, 2079-2088. [CrossRef] [PubMed]

33. Salerno, G.; Rebora, M.; Kovalev, A.; Gorb, E.; Gorb, S. Kaolin nano-powder effect on insect attachment ability. J. Pest Sci. 2020, 93, 315-327. [CrossRef]

34. Todd, J.W. Ecology and behavior of Nezara viridula. Annu. Rev. Entomol. 1989, 34, 273-292. [CrossRef]

35. Salerno, G.; Rebora, M.; Gorb, E.; Kovalev, A.; Gorb, S. Attachment ability of the southern green stink bug Nezara viridula (Heteroptera: Pentatomidae). J. Comp. Physiol. A 2017, 203, 601-611. [CrossRef]

36. Rebora, M.; Michels, J.; Salerno, G.; Heepe, L.; Gorb, E.; Gorb, S. Tarsal attachment devices of the southern green stink bug Nezara viridula (Heteroptera: Pentatomidae). J. Morphol. 2018, 279, 660-672. [CrossRef] [PubMed]

37. Salerno, G.; Rebora, M.; Gorb, E.; Gorb, S. Attachment ability of the polyphagous bug Nezara viridula (Heteroptera: Pentatomidae) to different host plant surfaces. Sci. Rep. 2018, 8, 10975. [CrossRef]

38. Salerno, G.; Rebora, M.; Kovalev, A.; Gorb, E.; Gorb, S. Contribution of different tarsal attachment devices to the overall attachment ability of the stink bug Nezara viridula. J. Comp. Physiol. A 2018, 204, 627-638. [CrossRef]

39. Salerno, G.; Rebora, M.; Piersanti, S.; Matsumura, Y.; Gorb, E.; Gorb, S. Variation of attachment ability of Nezara viridula (Hemiptera: Pentatomidae) during nymphal development and adult aging. J. Insect Physiol. 2020, 127, 104117. [CrossRef]

40. Yee, W.L. Behavioural responses by Rhagoletis indifferens (Diptera, Tephritidae) to sweet cherry treated with kaolin- and limestonebased products. J. Appl. Entomol. 2012, 136, 124-132. [CrossRef]

41. Barata, J.M.S.; Santos, J.L.F.; Da Rosa, J.A.; Comes, R.D. Evaluation of tryptamine behavior under the effect of contact with calcium hydroxide $\mathrm{Ca}(\mathrm{OH})_{2}$ : Mortality rates of Triatoma infestans and Rhodnius neglectus (Hemiptera, Reduviidae). An. Soc. Entomol. Brasil 1992, 21, 169-177. [CrossRef]

42. Boucher, J.; Adams, R.; Johnson, F.; Packauskas, R. Eggplant: Hydrated Lime as an Insect Repellent, 1991. Insectic. Acaric. Tests $1993,18,131$.

43. Strack, T.; Cahenzli, F.; Daniel, C. Kaolin, lime and rock dusts to control Drosophila suzukii. In Ökologschen Landbau Weiterdenken: Verantwortung Übernhemen, Vertrauen Stärken; Wolfrum, S., Heuwinkel, H., Wiesinger, K., Reents, H.J., Hülsbergen, K.-J., Eds.; Verlag Dr. Köster: Berlin, Germany, 2017; pp. 262-263.

44. Gorb, E.V.; Gorb, S.N. Functional surfaces in the pitcher of the carnivorous plant Nepenthes alata: A cryo-SEM approach. In Functional Surfaces in Biology—Adhesion Related Phenomena; Gorb, S.N., Ed.; Springer: Dordrecht, The Netherlands, 2009; Volume 2, pp. 205-238. 
45. Gorb, E.V.; Hosoda, N.; Miksch, C.; Gorb, S.N. Slippery pores: Anti-adhesive effect of nanoporous substrates on the beetle attachment system. J. R. Soc. Interface 2010, 7, 1571-1579. [CrossRef] [PubMed]

46. Colazza, S.; Peri, D.; Salerno, G.; Peri, E.; Lo Pinto, M.; Liotta, G. Xbug, a Video Tracking and Motion Analysis System for Linux. In Proceedings of the XII International Entomophagous Insects Workshop, Pacific Grove, CA, USA, 26-30 September 1999.

47. StatSoft Italia, S.R.L. Statistica (Data Analysis Software System), version 6; StatSoft Italia S.R.L.: Vigonza, Italy, 2001.

48. Sokal, R.R.; Rohlf, F.J. Biometry; W.E. Freeman and Company: New York, NY, USA, 1998.

49. Puterka, G.J.; Reinke, M.; Luvisi, D.; Ciomperik, M.A.; Bartels, D.; Wendel, L.; Glenn, D.M. Particle film, Surround WP, effects on glassy-winged sharpshooter behavior and its utility as a barrier to sharpshooter infestations in grape. Plant Health Prog. 2003, 4, 7. [CrossRef]

50. Kuhar, T.P.; Morehead, J.A.; Formella, A.J. Applications of kaolin protect fruiting vegetables from brown marmorated stink bug (Hemiptera: Pentatomidae). J. Entomol. Sci. 2019, 54, 401-408. [CrossRef]

51. Sterba, J.H.; Sperrer, H.; Wallenko, F.; Welch, J.M. Adsorption characteristics of a clinoptilolite-rich zeolite compound for Sr and Cs. J. Radioanal. Nucl. Chem. 2018, 318, 267-270. [CrossRef]

52. Gorb, E.V.; Lemke, W.; Gorb, S.N. Porous substrate affects a subsequent attachment ability of the beetle Harmonia axyridis (Coleoptera, Coccinellidae). J. R. Soc. Interface 2019, 16, 20180696. [CrossRef] [PubMed]

53. Clemente, C.J.; Bullock, J.M.; Beale, A.; Federle, W. Evidence for self-cleaning in fluid-based smooth and hairy adhesive systems of insects. J. Exp. Biol. 2010, 213, 635-642. [CrossRef] [PubMed]

54. Clemente, C.J.; Federle, W. Mechanisms of self-cleaning in fluid-based smooth adhesive pads of insects. Bioinspir. Biomim. 2012, 7, 046001. [CrossRef]

55. Féat, A.; Federle, W.; Kamperman, M.; Gucht, J.V.D. Coatings preventing insect adhesion: An overview. Prog. Org. Coat. 2019, 134, 349-359. [CrossRef] 